\title{
Function of Dreams: An Integrated Approach
}

\author{
Mohamed Omar Salem, MBChB, DPM, BCPsych, FRCPsych \\ Department of Psychiatry, Faculty of Medicine \\ United Arab Emirates University \\ Al-Ain, United Arab Emirates
}

\begin{abstract}
Throughout history, the fascinating world of dreams has attracted the attention of humankind, who sought to understand its meaning. This interest in dreams also reflects the human experience that many dreams have come true and brought news of the future. Science, philosophy, and religion have contributed to this common human experience. In this work I have reviewed the different aspects of dreams from physiological, psychological, parapsychological, psychiatric, and Islamic points of view. An account of the definitions and classification of the different types of dreams was followed by a brief description of the dream scene. The reviewer paid special attention to the precognitive function of dreams on the basis of the available evidence gathered from the most important research in this area. The article ends with a discussion aiming to explore, analyse, and integrate the different aspects of the phenomena into a holistic comprehensive framework.
\end{abstract}

Key words: dreams, sleep, precognition, dream recall.

Introduction

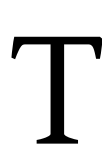
hroughout history, the fascinating world of dreams has attracted the attention of humankind, who sought to understand its meaning. The ancient Egyptians developed a system of dream interpretation and incorporated individual dream symbols. The Greeks developed a whole literature of dream interpretation based on symbols and on the belief in their prophetic nature. This historical interest in dreams may reflect the human experience that many dreams have brought news of the future and have come true.

Correspondence should be directed to

Mohamed Omar Salem, MBChB, DPM, BCPsych, FRCPsych Department of Psychiatry, Faculty of Medicine

United Arab Emirates University

PO Box 17666

Al-Ain, United Arab Emirates

mohamed.salem@uaeu.ac.ae
Spiritual and Religious Aspects of Dreams

The holy books of the monotheistic religions have confirmed the prophetic nature of some dreams. The Bible and the Glorious Qur'an document the story of Prophet Joseph's interpretation of the King of Egypt's dream averting seven years of famine in the area. ${ }^{1}$

According to the prophetic teaching, Muslims classified dreams into three subtypes. These are truthful dreams or visions, self-talk dreams, and jumbled dreams. Truthful dreams or visions ( $\left.r u^{\prime} y \bar{a}\right)$ are dreams of divine origin and carry important messages. They are either good tidings from God, encouragement to do good things and guidance to them, or warnings. The warning dream is a message to the dreamer to take precaution to avoid some threat or danger in the near future or to prepare him for some bad news. ${ }^{2}$ Self-talk dreams reflect the dreamer's concerns and preoccupations. Bizarre and jumbled dreams have no significance.

According to the Islamic teachings, truthful 
dreams are human faculty and can occur to believers and nonbelievers alike. However, their occurrence can be increased if the dreamer is a believer who leads a righteous, truthful life: ${ }^{3}$

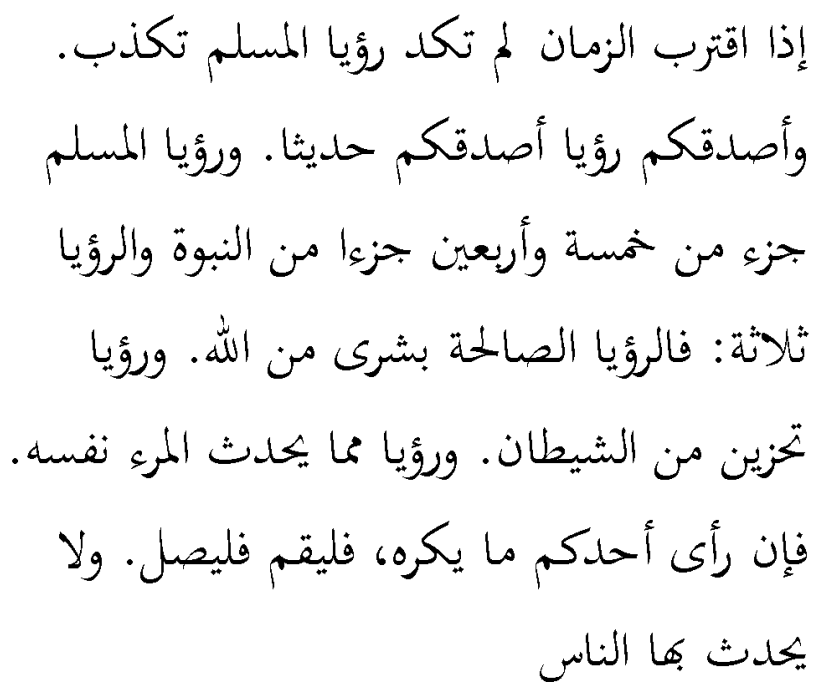

When the time [Day of Judgment] draws near a believer's dream can hardly be false. And the truest vision will be of one who is himself the most truthful in speech, for the vision of a Muslim is one of 45 parts of prophecy, and dreams are of three types: one good dream, which is a sort of good tidings from Allah; the evil dream, which causes pain is from the Satan; and the third one is a suggestion of one's own mind; so if any one of you sees a dream that he does not like he should stand up and offer prayer and he should not relate it to people. 4,5

As dreams occur during sleep, it might be appropriate to start discussing aspects related to this curious state of existence.

\section{Types of Sleep}

Sleep is an altered state of consciousness that occupies nearly one-third of our lives. According to various parameters, it can be classified into two types:

1. Quiet sleep: As the subject falls into deeper and deeper stages of sleep (stages 1-4), the brain waves become slow, large, and rather irregular, indicating a lower level of brain activity. Breathing and heart rate are slow and regular, and the eyes are motionless, and thus this state is termed nonrapid eye movement (NREM) sleep. The brain's metabolic rate decreases by
25-30\%, compared to wakefulness.

2. Active sleep: Also called paradoxical sleep because it is qualitatively different from quiet sleep. The EEG becomes quite similar to that found when the subject is awake. However, the brain is largely isolated from its sensory and motor channels, and it is more difficult to wake someone from this type of sleep than the deep stage 4 sleep. The brain metabolic rate increases somewhat compared with wakefulness. Breathing and heart rate accelerate, and the eyes move in quick bursts lasting from 10-20 seconds. The direction of eye movements could be up and down or side to side and in synchrony, hence the term rapid eye movements (REM) sleep. Muscle tone is nearly absent, and we are almost paralyzed during this type of sleep. Only the heart, the diaphragm, eye muscles, and smooth muscles are spared. ${ }^{6}$ This atonia might be beneficial as it protects the dreamer from acting out the dreamed actions.

Indeed, the special quality of REM sleep has led some investigators to consider REM episodes not to be sleep at all, but rather a third state of existence, as it is in many ways different from NREM sleep and from waking. ${ }^{7}$

Both types, quiet and active, alternate in 90-minute cycles throughout the night with NREM sleep followed by REM sleep. The latter lasts approximately 10 minutes at the start of sleep and increases gradually to 20-30 minutes by the end of the night. When woken during REM sleep, about $80 \%$ of sleeping volunteers will report that they have been dreaming. However, this percentage drops to only $15 \%$ if woken from NREM sleep. NREM dreams are shorter, less vivid and less visual than REM dreams, and the dreamers often describe themselves as having been thinking rather than dreaming. ${ }^{8}$

Surprisingly enough, the exact function of sleep is still unknown, but there is need for sleep, and there is need for its both types. ${ }^{9}$ NREM sleep is thought to have some restorative anabolic function, ${ }^{10}$ whereas REM sleep was claimed to be related to consolidation of memory. ${ }^{11}$ As mentioned earlier, REM sleep was also found to be associated with dreaming.

\section{Dreams}

A dream is a series of episodes that seem real at the time. Dreams are generally forgotten within minutes after they have occurred. Such fragile memory of normal dreams, may serve to protect us from confusing 
the memories of our real waking life with those of our dreams.

\section{Functions of Dreams}

Most civilizations associate dreams with messages of prophetic nature, including warnings and omens. Sigmund Freud in The Interpretation of Dreams explained dreams solely on the basis of an intrapsychic process. As he was biased to his atheistic philosophy, he denied the existence of precognitive dreams. However, researchers surveying dozens of studies of dreaming concluded that, while there is strong evidence that the content of many dreams has psychological meaning, none of the studies supports Freud's distinction between manifest and latent content. These researchers came to question the concept of "dream work" and the idea that dreams represent wish fulfillment. ${ }^{12,13}$

The activation-synthesis hypothesis postulates that dreams are a reflection of the brain's aroused state during active sleep.

\section{Dreams and Scientific Discoveries}

Cartwright suggested that dreams might have a problem-solving function. ${ }^{14-16}$ Dreams of scientific discoveries and creativity can be a good example of this function. Several scientific or technological discoveries have been realized as a result of dreams. The following are just some examples: ${ }^{17}$

1. August Kekule guessed the benzene ring structure after seeing two dreams: a snake coiling its tail into its mouth, and the dancing little girls; with the last one catching the hands of the first one.

2. Elias Howe discovered how to put the thread into a sewing machine through a dream suggesting a little spear with a hole at the upper end.

3. Niels Bohr, during his studies on the structure of the atom, had a dream in which he saw planets connected to the sun with threads and turning around it. From this dream he conceived the resemblance between what he had seen and the structure of atoms.

Prodromal dreams signalling the onset of physical illness suggest another function of dreaming. Some dreams seem to be especially good at registering subtle internal and external signals that often go undetected in waking life, making them potentially useful for picking up early signs of physical illness. Many case reports of warning dreams for brain tumors, cancer, and other physical problems have been documented, which were occasionally associated with suggested ways of seeking help or management. In some cases dreamers reported dreams in which healing spontaneously occurred while they were dreaming. ${ }^{17}$

However, the occurrence of precognition (the ability to predict future events) in dreams has been reported by a large number of people, ${ }^{18}$ documented experimentally in a series of stunning experiments ${ }^{19}$ and will be discussed in more detail later in this review.

\section{Types of Dreams}

Western dream researchers classify dreams into ordinary dreams and paranormal or psychic dreams. ${ }^{20}$ Ordinary dreams are the everyday dreams that usually reflect some of the individual's concerns and preoccupations and might be jumbled or bizarre. They usually fade quickly upon waking. On the other hand, paranormal or psychic dreams seem to have special qualities. They are usually vivid and intense and make a strong impression that they remain in the mind longer than an ordinary dream. Occasionally, they have unusual details including colors, texture, and sounds. A clear memory of the dream and a sense of its importance are also characteristic of this type of dream that is usually uninterrupted and nondigressive. Waking up is often smooth and unconfused. Most people seem to be able to distinguish between the ordinary everyday dreams and psychic dreams, which are quite distinctive and peculiar. However, such distinction is occasionally difficult, when the dream content is too general or vague. Psychic dreams tend to cluster around events that are of emotional significance and events of importance, even if they are unanticipated.

Western dream researchers classify psychic dreams into precognitive and telepathic varieties. ${ }^{19-22}$ Precognitive dreams have the ability to predict future events, gaining information across time. Telepathic dreams communicate events happening at the same time or earlier but outside the dreamer's range of knowledge at the time. Therefore, telepathic dreams gain information across space. The phenomenon of shared dreams occurs when two or more people have the same dream at the same time. Lucid dreaming refers to the experience when the dreamer is aware that he is dreaming and can occasionally manipulate the content of the dream.

Psychic dreams lie on a continuum from being totally literal to being totally symbolic, with most of them falling somewhere in between. Psychic dreams 
represent a real challenge to science, as they cannot be explained by any known scientific theory. 23

In comparison with ordinary dreams, for a particular person, psychic dreams are relatively rare. Many people report the occurrence of such dreams only once or twice in their lives. However, some people seem to be more gifted for precognitive dreams than others. Also, some studies suggest that psychic dreams seem to be over-represented in certain families, and to be more common with women. ${ }^{21-24}$

\section{Dream Recall}

Dream recall might be difficult because recalling a dream is a reconstructive process during the waking state. Consequently, it could be occasionally a distorted version of the actual dream. Some people report that they have no dreams at all. Obviously, the studies of REM sleep prove that this is not true. A possible explanation is that people who do not pay attention to their dreams may unconsciously block their fragile dream memory. Also, lack of acceptance of the significance of dreams in a family inhibits some family members from discussing them. Children, fearful of family disapproval or sarcastic comments, may even learn to subconsciously block memories of their dreams when they do occur. On the other hand, individuals who value the importance of dreams, permit and encourage themselves to observe their own dreams. Also, people who pay attention to their dreams and remember them seem to have more psychic dreams than people who deny their existence.

As dreams tend to be forgotten quickly, it is advisable to write them down in detail upon waking or to recount them to someone. Generally, dreamers are advised to maintain a dream diary to record their dreams and to examine them regularly for reflection and for possible correlation with future events.

\section{The Dream Scene}

The dream is usually divided into dramatic scenes with the dreamer taking one or more of the following roles during the dream: observer dreams, when the dreamer only observes the events; participant dreams, when the dreamer is one of the characters; vicarious dreams, when the dreamer identifies with other characters (another identity); or visitation dreams, when the dreamer visits some people of emotional significance or is visited by them. This last type also includes visits from the dead, which are usually vivid and valued in many cultures. ${ }^{21}$

However, the details of the content of dreams tend to differ according to the culture, gender, and personality background of the dreamer.

It is important to note that to consider a dream to be psychic, studies usually apply strict criteria, including:

1. The dream must have been told or recorded before its fulfillment.

2. It must include enough details to fix the occasion of fulfillment and to render chance fulfillment unlikely.

3. It must be of such a nature that the percipient could not in anyway have caused its fulfillment.

In this paper I shall review some of the major Western studies covering these phenomena.

\section{Dream Studies}

Montagne Ullman, an American psychiatrist, was one of the first scientists to investigate psychic dreams in a laboratory setting. In his clinical practice he noticed that many of his patients reported precognitive and telepathic dreams. In 1962, in association with Stanley Krippner, a psychologist, he founded the Maimonides Dream Laboratory in New York to study the phenomena under laboratory conditions. The laboratory continues its work to the present day and has published extensive literature related to their studies. The technique of their experiments was to attach electroencephalogram (EEG) electrodes to the head of the subject under experiment, an electro-oculogram (EOG) to the eyelids, and an electromyogram (EMG). The subject would go to sleep in a soundproof sleep laboratory. He would be woken when his EEG showed him to be at the end of an REM period and asked to recount the dream he has just had. An independent investigator would later examine the correlation between the reported dreams and any possible psychic phenomena. The results of nine out of 13 studies were statistically significant, indicating the presence of precognitive and telepathic elements in their subjects' dreams. ${ }^{19}$

Joseph Banks Rhine of the Duke Parapsychology Laboratory collected several thousand accounts of psychic experiences, the majority of which were precognitive dreams. More recently, two large random population samples were asked about telepathic and 
precognitive dreams. Almost a third reported psychic dreams. In Rhine's collection, women outnumbered men two to one. 18,23

Arthur Hastings a Canadian dream researcher, has published useful works in precognitive dreams. He concluded from his research that precognitions do occur in dreams and provide functional information and guidance for waking life. He observed that for certain kinds of events precognitive dreams presented what was going to happen and also what he needed to do about them. Frequently, such dreams give a useful metaphoric view of the coming event. From his experience he learned to watch his dreams carefully as he undertook new projects or as important events in his life approached. He used the dream as a way of expanding his awareness of the possibilities of a situation and of responding to that potential. He accepted the information and perspective as likely to be useful to him, and he tried to understand the meanings as best as he could. However, he noticed that, if one wishes to use dreams for guidance, there must be no conscious interference with the content and form of the dream. ${ }^{25}$

D. Ryback, an American clinical psychologist, spent 15 years studying the phenomena of psychic dreams with his assistant, L. Sweitzer. Their samples included university students and a vast number of the general population. They published their results in the book Dreams That Come True. ${ }^{21}$ They concluded that precognitive dreams not only exist but also are very common. According to their findings, one out of the 12 people studied had psychic dreams. In the book, they analyzed the results and suggested some maneuvers to understand the meaning of dream symbols. They recommended the identification of the elements of the dream (people, places, actions) and the application of word associations to each dream element. ${ }^{21}$

Keith Hearne, a British dream researcher, studied dream telepathy and premonitions. In response to his request for premonitions (forewarning dreams in particular) in a national newspaper, he received 450 replies, of these, 165 were convincing accounts. Most premonitions were related to death or unpleasant happenings (84\%), and many of them were very specific. Again, the majority of his subjects were women. ${ }^{20}$

\section{Precognition of Disasters}

At least two serious studies of precognitions have been done on the dreams that occurred before great national disasters. The first study was related to the Aberfan disaster, which occurred in this small Welsh mining village on October 21,1966 , when 500,000 tons of coal waste buried the village school just at the beginning of the school day. The second study was done on the Teton dam disaster in Idaho, in the western United States, which occurred in June 1976, when the Teton dam collapsed, causing massive flooding. J.C. Barker did the first study, whereas L. Wood-Trost carried out the Idaho study. In each study, the researcher checked for evidence that the dream had been described to someone else before the event occurred. In each study there were at least two premonitory dreams that offered definite evidence that precognition does indeed occur. For example, Eryl Jones, a 10-year-old girl and one of the victims in Aberfan, told her mother the day before the catastrophe that she dreamed that "I went to school and there was no school there, something black had come down all over it." It was noticed that the pattern of dreams was similar in both studies. There was a gradual buildup in the number of dreams during the week before the disaster, and a peak occurred the night before the catastrophe. ${ }^{26-27}$

\section{Special Cases of Gifted Dreamers}

Barbara Garwell lives in Hull, United Kingdom, and has a reputation for unusually accurate dream predictions. In March 1981 she dreamed about the shooting of Ronald Reagan, which occurred three weeks later. In September 1981 Mrs. Garwell dreamed of the assassination of President Anwar al-Sadat of Egypt with most of the details of the scene. Again, it was three weeks before the incident, which occurred on October 6. However, there was a small mistake in this dream as she reported the number of assassins to be two, but they were actually four. On both occasions, there were witnesses who confirmed that Mrs. Garwell told them about the dream before the actual events occurred. Dr. Hearne spent more than one year with Mrs. Garwell, studying and examining the precognitions in her dreams. ${ }^{24,28}$

John William Dunne is a British engineer who had a series of precognitive dreams that convinced him that dreams have access to the future. In his book $A n$ Experiment with Time, he describes his dreams, which are very convincing and amazing. He postulated a theory that "precognitive dream experiences are simply dreams displaced in time." He suggested that the 
dreamer stands outside the flow of time and can see both forwards and backwards in time, thus gaining an access to events that occur in the future. ${ }^{29}$

\section{Other Evidence}

In response to a questionnaire published in The Times in October 1980, 42\% of respondents had a dream that came true concerning events that they did not know about or expect before the dream. Of these, about two-thirds had had such a dream more than once. ${ }^{30}$ John Beloff, a professor of psychology at the University of Edinburgh, has headed researchers interested in the correlation between dream predictions and their subsequent validation. Initial results have shown highly positive results. ${ }^{23}$

\section{Evidence from History}

Abraham Lincoln, the 16th president of the United States, dreamed of his own assassination in 1865 the night before it actually occurred. He saw the servants of the White House running around a coffin draped in the American flag and telling one another that the president was killed. Next morning he told many people of his dream. In the evening he went to see a play at a theater, where he was shot and died. ${ }^{2}$

The discovery of the secret tunnel and the subsequent building in 1161 of the lead barrier surrounding the Holy Room in the Prophet's Mosque in Madina in present-day Saudi Arabia resulted from a dream. One night of that year, after the night prayer, Sultan Nūr alDīn Mahmūd Zinkī (d. 1174) had a recurrent vivid dream. He saw the Prophet Mohammad allugale asking him to save him from two strangers. On the following day, he left for Medina, where he later could recognize the two men. Searching their house, they discovered a secret tunnel they had been digging to get access to the Prophet's room. Apparently, they were plotting to abduct the Prophet's body through this tunnel. Obviously, many people had witnessed this story with its related historical events. ${ }^{3}$

In June 1944, during the World War II, U.S. Gen. Eisenhower, who later became its 34th president, had a dream that changed the course of the war. A few days before the scheduled date of the landing in Normandy, he saw in a dream that a big storm broke out and overturned the landing crafts. That dream caused him to make the landing earlier than the appointed time. As Eisenhower had seen in his dream, a big storm broke out some days after the landing had started. ${ }^{2}$

\section{Psychiatric Aspects of Dreams}

Eliciting dreams in psychiatric interventions has been emphasized by many authors. ${ }^{32}$ Dreams are frequently reported in psychiatric interviews by patients who hope that the psychiatrist may be able to explain or comment on them. Unfortunately, the psychiatrist usually seems to be uninterested and ignores them. Eliciting dreams could facilitate patients who are otherwise inhibited to talk about their personal lives. It can lead to an appreciation of conflicts and concerns that the patient might not otherwise be able to express. Apparently the vast majority of dreams are of the ordinary type, which is affected by many factors. including physical and psychological factors. Anxious and depressed patients tend to have more nightmares and anxiety dreams, whereas in psychosis, dreams tend to be more bizarre. However, if a patient reports a possible psychic dream according to his view, it is important to discuss it further with him, explore his viewpoint further, and encourage him to take a positive approach towards his dream, including the unpleasant ones.

Jung, a Swiss psychiatrist, said: "Dreams contain a message from our soul, which should be listened to. With encouragement and training, this message can be clarified and amplified once the dreamer has awakened." 33

\section{Discussion}

Several alternative explanations were given to the interesting phenomena of psychic dreams. One argument was that we only remember those dreams that come true and tend to forget the majority of dreams that were not true. However, chance coincidence cannot explain the phenomena because of the unexpected nature of many precognitive dreams. In addition, the research requirement for the studied dreams to include enough details to fix the occasion of fulfillment renders chance fulfilment unlikely.

Psychic dreams strongly shake our current scientific conceptualization of the physical world. They teach us that we can gain knowledge through a nonsensory link between the objective outside world and our subjective inside world. How can we know things in the dream state that we have no knowledge of in full consciousness?

Precognitive dreams are in particular fascinating, 
because they seem to present us with a bridge across time. Normally we think of time as being a straight line. There is a past, a present, and a future. The movement is always forward, and this flow of time is called the time arrow. The laws of causality as we understand them fall into this pattern. So, for example, the future cannot affect the past.

Precognition in dreams raises the question about the reality of this arrow, with the possibility that the past, the present, and the future all stand together somewhere. Does knowledge of the future allow one to interact with the future and alter its outcome? Could the precognitive dream be considered a warning, or was it fate, and no one could change it? There must be some meaning to these warnings. Precognitive dreams imply that the future has been already written. If so, where and by whom? The implication of this question is that a supreme being should be there! Obviously, this could be an important link between the physical perceptual world and the unseen spiritual world, between science and religion, and between human beings and their Creator. Dream researchers observed that deliberately avoiding the dream circumstances could avert some disasters warned about in precognitive dreams. The dreamer who discourages the pattern depicted in a precognitive dream can apparently disrupt the outcome. So, it seems that although the future may be written, the script can be revised. It is interesting to note that this concept is compatible with the Islamic teachings of destiny. Muslims are taught that the events of a warning dream can be altered if the dreamer follows certain prophetic instructions, including saying prayers. ${ }^{31}$

Another point is the relationship between mind and brain. One view. the dualistic theory, hypothesizes that the mind and brain are different and are linked together in some way. It postulates that the brain does not create consciousness but acts as a transmitter of a beam of consciousness, which has its origins outside the brain. Sense data are transformed by the brain for transmission to the mind. Mind in its turn can will an action, transmit it to the brain and so initiates brain processes and actions. Although memories are held partly within the brain, a large part of memory is stored external to the brain, where personal identity is located. ${ }^{34}$ This theory implies that personal identity might exist independently of the body. Transmission theories allow the possibility of soul, personal survivor, and extrasensory perception as evidenced by the phenomena of precognition, clairvoyance, and telepathy and out-of-body experiences. Supporters of this theory include many scholars such as Descartes and William James and Sir John Eccles, a distinguished neurophysiologist and Nobel Prize winner. Eccles suggested that at the interface between brain and mind, the "dendron" (a hypothetical region of the nerve cell processes of the brain) links with the "psychon" (the hypothetical atom of the mind). ${ }^{34}$

In Islamic literature we have a lot of interesting correlations. Some Muslim authors postulated that, when sleep becomes deeper and deeper, the soul (mind) can be liberated from the constraints of sensations and becomes free to get reflections from the unseen (spiritual) world. If the reflections are clear, the dream will be literal; otherwise it would be symbolic. ${ }^{2}$ Could this liberation correspond to the state of the REM episode (the third state of existence), which follows the deepest stages of sleep? Could the rapid eye movements be correlated with the soul vibrations, as alluded to in the saying of the Messenger Muhammad and commenting on the gaze of the dead.

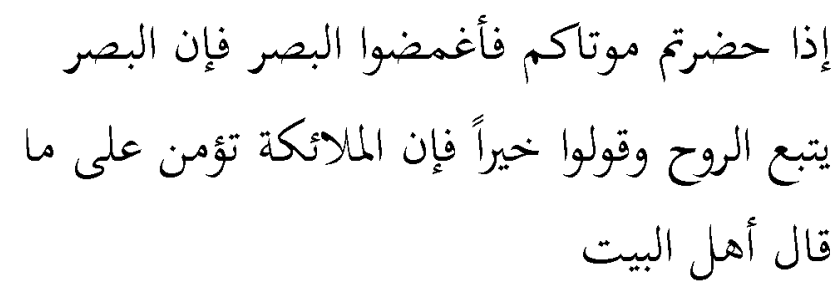

If you attend your dead, close his eyes because the eyes (gaze) follows the soul, and mention only good things as the angels may confirm what the household (relatives) say. 35

We can conclude that our scientific knowledge by itself is not yet adequate to explain these phenomena. Perhaps contemporary Muslim scholars need to lead the human knowledge guided by the light of the divine revelation. It is now time for the East and the West to create a new science, which integrates both the objective and the subjective: science and religion.

\section{References}

1. Winson J. The meaning of dreams. Sci Am 1990;263:86-8,90-2,94-6. Available from: http://inside.bard.edu/ luka/documents/WinsonDrea ms.pdf. 
2. Gulen MF. Understanding and belief: the essentials of Islamic faith. Izmir, Turkey: Kaynak; 1997.

3. Najātī MU. Al-Dirāsāt al-nafsānīya 'inda al-'ulamā' al-muslimin. Cairo: Dar El-Shurūq; 1993.

4. Șaḥị̣ Muslim. Kitāb al-ru'yā (42), number 2263. Available from http://www.muhaddith.org.

5. Șaḥịh Muslim. Șiddīqī AḤ, translator. Lahore: Sh. Muhammad Ashraf; 1987:1224.

6. Aserinsky E, Kleitman N. Regularly occurring periods of eye motility and concomitant phenomena, during sleep. Science. 1953;118:273-4.

7. Hilgard ER, Atkinson RL. Hilgard's introduction to psychology. 13th ed. Fort Worth: Harcourt College Publishers; 2000.

8. Gross RD. Psychology: the science of mind and behaviour. London: Hodder \& Stoughton; 1996.

9. Gleitman LR. Psychology. 4th ed. New York and London: W.W. Norton \& Co.; 1995.

10. Horne JA. Why we sleep: the functions of sleep in humans and other mammals. Oxford and New York: Oxford University Press; 1988.

11. Evans CR, Evans P. Landscapes of the night: how and why we dream. New York: Viking; 1984.

12. Fisher S, Greenberg R. The scientific credibility of Freud's theories and therapy. New York: Basic Books; 1977.

13. Fisher S, Greenberg, R. (1996) Freud scientifically appraised. New York: Wiley.

14. Cartwright R. Happy endings for our dreams. Psychology Today. 1978 Dec:66-7.

15. Cartwright R. "Masochism" in dreaming and its relation to depression. Dreaming. 1992;2:79-84.

16. Cartwright R. Dreams and adaptation to divorce.

In Barrett D, editor. Trauma and dreams. Cambridge, MA: Harvard University Press; 1996:179-85.

17. Van de Castle RL. Our dreaming mind. New York: Ballantine Books; 1994.

18. Rhine LE. ESP in life and lab. New York: Macmillan; 1967.

19. Ullman M, Krippner S, Vaughan A. Dream telepathy: experiments in nocturnal ESP. New York: Macmillan; 1989.

20. Hearne KMT. A survey of reported premonitions and of those who have them. Journal of the Society for Psychical Research. 1984;52:261-70.
21. Ryback D, Sweitzer L. Dreams that come true. London: Diamond Books; 1993.

22. Hearne KMT. A nationwide mass dream-telepathy experiment, Journal of the Society of Psychical Research. 1989;55:271-4.

23. Fenwick P, Fenwick E. The hidden door: understanding and controlling your dreams. London: Headline; 1998.

24. Hearne KMT. An analysis of premonitions deposited over one year, from an apparently gifted subject. Journal of the society of psychical research. 1986;53:376-82.

25. Hastings AC. Dreams of future events: precognitions and perspectives. Journal of the American Society of Psychosomatic Dentistry and Medicine. 1977;24:51-60.

26. Barker JC. Premonitions of the Aberfan disaster. Journal of the Society for Psychical Research. 1967;44:169-81.

27. Wood-Trost L. Possible precognitions of the Teton Dam disaster in Idaho. Journal of the Society for Psychical Research. 1981;51:65-74.

28. Garwell B. Dreams that come true: a medium's predictions from the past and visions of the future. London: Thorsons; 1996.

29. Dunne JW. An Experiment with time. London: Faber and Faber; 1927.

30. The Times, newspaper, All October issues (1980), London. [Comment: the published survey covered the whole month]

31. Twaijry HA. Kitāb al-ru'yā. Riyadh: Al-Liwa Publishers; 1992.

32. Mitchison S. The value of eliciting dreams in general psychiatry, Advances in Psychiatric Treatment. 199;5:296-301. Available from: http://apt.rcpsych.org/cgi/reprint/5/4/296.

33. Jung CG. The undiscovered self: with symbols and the interpretation of dreams. Princeton, N.J.: Princeton University Press; 1992.

34. Eccles JC. How the self controls its brain. New York: Springer-Verlag; 1994.

35. Sunan Ibn Mājah. Kitāb al-janā'iz (6). Bāb mā jā' fĩ taghmīọ al-mayyit (6). No. 1455. Available from http://muhaddith.org. 